de Gruyter Lehrbuch

Heinz Schade

Tensoranalysis 



\section{Heinz Schade}

\section{Tensoranalysis}


Autor

Professor Dr.-Ing. Heinz Schade

Hermann-Föttinger-Institut für Strömungsmechanik

Technische Universität Berlin

Straße des 17. Juni 135

D-10623 Berlin

Das Buch enthält 25 Abbildungen.

(0) Gedruckt auf säurefreiem Papier, das die US-ANSI-Norm über Haltbarkeit erfüllt.

Die Deutsche Bibliothek - CIP-Einheitsaufnahme

\section{Schade, Heinz:}

Tensoranalysis / Heinz Schade. - Berlin ; New York :

de Gruyter, 1997

(De-Gruyter-Lehrbuch)

ISBN 3-11-014740-8 brosch.

ISBN 3-11-014741-6 Gb.

(C) Copyright 1996 by Walter de Gruyter \& Co., D-10785 Berlin

Dieses Werk einschließlich aller seiner Teile ist urheberrechtlich geschützt. Jede Verwertung außerhalb der engen Grenzen des Urheberrechtsgesetzes ist ohne Zustimmung des Verlages unzulässig und strafbar. Das gilt insbesondere für Vervielfältigungen, Übersetzungen, Mikroverfilmungen und die Einspeicherung und Verarbeitung in elektronischen Systemen.

Printed in Germany

Druck: Gerike GmbH, Berlin. - Buchbinderische Verarbeitung: Mikolai GmbH, Berlin. Einband: Hansbernd Lindemann, Berlin. 